\title{
Spirituality and Entrepreneurial Failure
}

\begin{abstract}
The paper examines how spirituality affected entrepreneurs' experience of venture failure and its aftermath. Failure is an important but under-researched part of the entrepreneurial process. We implement a qualitative, narrative research design and present a collective story of nine spiritually oriented entrepreneurs' experience of failure. Overall, the paper extends research beyond the current psychological focus to a spiritual perspective. Findings show that entrepreneurs' experience of failure was different from that predicted by psychological theories. Entrepreneurs deeply engaged with failure instead of indulging in self-deception and other cognitive strategies to cope with the negative emotions of failure. Furthermore, findings revealed a rare, unexpected positive outcome from failure - entrepreneurs evolved spiritually through experiencing this negative life event.
\end{abstract}

\section{Keywords:}

Spirituality, failure, venturing 


\section{Spirituality and Entrepreneurial Failure}

Scholars are beginning to acknowledge the role of spirituality in entrepreneurship and have adopted varied approaches to investigate this phenomenon (Jackson \& Konz, 2006) Importantly, research suggests that spirituality fosters the intention to start-up ventures (Judge \& Douglas, 2013; Nwankwo, Gbadamosi \& Ojo, 2012; Pavlovich \& Corner, 2013) and influences entrepreneurial decision making (Nolan, 2005). Research also contends that entrepreneurs integrate their spiritual beliefs in a manner that allows them to fulfil their business obligations and helps their ventures to succeed (Pio, 2010). Furthermore, studies find that entrepreneurs' spiritual practices enhance their ability to cope with stressful business situations (Herriott, Schmidt-Wilk \& Heaton, 2009) and shape venture culture (Jackson\& Konz, 2006). Evidence suggests that entrepreneurs view venture founding and managing as a part of their spiritual journey (Kauanui, Thomas, Sherman, Waters, Gilea, 2010; Pavlovich \& Corner, 2013) and create a work environment that acknowledges work and play as integrated aspects of the workplace (Kauanui et al., 2010).

Despite this promising research, the literature remains silent on the role of spiritual processes in the midst of entrepreneurial failure. This is surprising because failure can wreak a spiritual havoc for entrepreneurs. In particular, failure damages personal relationships (Singh , Corner \& Pavlovich, 2007; Cope, 2011) and some entrepreneurs can even slide into the murky path of crime to recover from losses and deep sense of shame (Smith \& McElwee, 2011). The uncertainty of what lies ahead after the failure of the business can make life seem so daunting that an entrepreneur could avoid starting up a future venture (Hayward, Forster, Sarasvathy \& Fredrickson, 2010). Given the significant impact of failure on entrepreneurs' lives, it is curious that the role of spirituality in entrepreneurial failure remains relatively unexamined. This lack of research becomes even more surprising when one considers that spirituality mitigates the negative effects of highly stressful life events, like a cancer diagnosis 
(Speca et al., 2000). Such research would likely add to our understanding of mechanisms whereby entrepreneurs minimize the effects of venture failure. Such mechanisms would be of interest theoretically in that they would extend our knowledge of factors that lead to future venture founding despite entrepreneurial failure. They would also be of interest to policy makers looking to develop programs to encourage failed entrepreneurs to attempt venture founding again. Given research that suggests spiritual practice leads to clearer perception, an examination of spirituality in the context of entrepreneurship may even highlight mechanism that potentially prevent failure and its often damaging consequences.

The purpose of this paper is to empirically examine the spiritual experiences of entrepreneurs as they deal with venture failure and its aftermath. We thus address the research question “How does spirituality affect entrepreneurs’ experience of venture failure?” We consider how spirituality shapes their decisions and actions with respect to venture failure. For example, Does spirituality facilitate the decision making required of failing entrepreneurs as they manage the practical aspects of closing down a business and plan to move on to the next stage of their lives? To address the research question, we implement a qualitative, narrative approach and present a collective story of the role of spirituality in the lives of entrepreneurs whose ventures failed. Such a story enables us to give voice to a group, failed entrepreneurs, who have potentially been marginalized through the stigma attached to failure. The story highlights a possible mechanism for personally managing failure that may minimize the negative aspects of this experience and even provide a positive transformation from it (Cope, 2011). In the following sections, we present background literature, describe the research methodology used, report empirical findings, and discuss the implications of this study for the wider entrepreneurship literature. 


\section{BACKGROUND}

Management research has increasingly acknowledged the importance of spirituality in work place (Jackson \& Konz, 2006; Karakas, 2009). While a variety of definitions of work place spirituality have emerged, we found common recurring themes that surfaced from a number of definitions. Work place spirituality involves finding meaning and purpose in life (Mitroff \& Denton, 1999; Kauanui et al., 2010 ); living life in an “integrated” manner (Mitroff \& Denton, 1999 and being interconnected (Mitroff \& Denton 1999; Mitroff, 2003; Jackson, 1999) with higher power, self, other people, one’s environment (Liu \& Robertson, 2011) and work (Jackson, 1999; Kauanui et al., 2010; Pio, 2010). It has also been described as the force of life that provides a sense of harmony (Pio, 2010), peace, and tranquillity (Mitroff, 2003).

Scholars are beginning to explore spirituality and its role in entrepreneurship, against this backdrop of accumulating knowledge with workplace spirituality. We see two themes dominating the few studies published to date. The first theme focuses on entrepreneurs themselves and examines the influence of spirituality on their actions and behaviours when founding ventures. Several studies show that entrepreneurs tend to integrate spirituality with venture related decisions and activities (Jackson \& Konz, 2006; Kauanui et al., 2010; Pavlovich \& Corner, 2013; Pio, 2010). Several studies find that entrepreneurs’ spiritual practices motivated venture start-ups (Judge \& Douglas, 2013; Pavlovich \& Corner, 2013) and stimulated creativity in overcoming the liabilities of newness (Judge \& Douglas, 2013). Herriott et al. (2009) examine the effects of successful entrepreneurs' meditation practice and find that founders developed a stable inner core as well as enhanced intuition and awareness which allowed them to embrace the environment and the wider community. Other research shows that spiritual entrepreneurs regard and utilise their business as part of their spiritual journey (Kauanui et al., 2010; Pavlovich \& Corner, 2013). Pio (2010) explores the link 
between spirituality and entrepreneurship by examining the case of immigrant women entrepreneurs in Sweden and finds that the entrepreneurs balance their spiritual traditions with the decision making in their business in a way that is not in contradiction with the values of the host country.

The second theme focuses on ventures; examining the effects of entrepreneurs' spirituality on their fledgling firms. For example, Judge and Douglas (2013) report that founders' spiritual beliefs informed their visions for nascent ventures. Jackson and Konz (2006) find that spirituality shapes the culture of entrepreneurial ventures. Kauanui et al. found (2010) that work and play were not seen as separate elements in the work environment of businesses founded by spiritually oriented entrepreneurs. Pavlovich and Corner (2013) find evidence that entrepreneurs' spiritual practice create pro-social, entrepreneurial intentions which lead to the creation of shared value -- value which puts people and community interests before profit (Porter \& Driver, 2012).

Taken collectively, existing empirical research provides substantive support for the influence of spirituality on entrepreneurial decisions and behaviour which, in turn, affect founded ventures. However, the bulk of the research examines entrepreneurial success so that we have little knowledge of how spirituality affects entrepreneurs and their behaviours when ventures fail. This lack of research means that we remain uninformed about a large part of the domain of spirituality and entrepreneurship given that 50 percent of small venture founding are estimated to fail within the first five years of existence (Pinfold, 2000). Moreover, we expect that spirituality has a role to play in entrepreneurial failure given spirituality's role in meaning making (Karp, 2006) and in individuals achieving peace and harmony (Mitroff, 2003) regardless of what is happening in their lives. We contend that entrepreneurs' spiritual practice could help them deal with the deep grief and other psychological and physiological problems such as depression, anxiety, anger, phobias, panic attacks, weight loss, high blood 
pressure, insomnia and exhaustion experienced due to venture failure (Cope, 2011; Singh et al., 2007).

Failure can replace the promise of perceived entrepreneurial opportunities with a disheartening reality of turmoil and unpredictability and can "discourage even the most resilient of individuals” (Shepherd, Covin \& Kuratko, 2009: 598). As such, there has been a growing scholarly interest in examining the processes and factors that enable entrepreneurs to effectively recover from failure. An understanding of recovery is important because grief, for example, can interfere with an entrepreneur’s ability to learn from failure (Shepherd, 2003) and may prevent the founding of future ventures (Shepherd, Kovin \& Kuratko, 2009). Studies exploring recovery from failure rely mainly on psychological theories such as the grieving process (Shepherd, 2003), coping (Singh et al., 2007), and resilience (Hayward, et al., 2010). The following paragraphs consider these theories.

Shepherd (2003) explores recovery as a grieving process. He conjectures that entrepreneurs experiencing failure oscillate between a loss oriented recovery strategy (focusing on and working through the practical aspects of venture loss) and restoration oriented strategy (avoiding thoughts of failure and suppressing emotions). He argues that either strategy on its own creates further negative consequences for the entrepreneur. Scholars have even introduced the notion of anticipatory grief where entrepreneurs facing the likelihood of venture failure begin the grieving process before the venture actually fails (Shepherd, Wiklund and Haynie, 2009). The authors argue that in some situations the delaying of business failure can help balance the financial and emotional costs of failure and enhance recovery. With respect to coping, Singh et al. (2007) show that entrepreneurs use two kinds of coping strategies: problem-focused coping and emotion-focused coping. Problemfocused coping involves management of the practical aspects of failure and entrepreneurs use this type of coping to dealing with the practical and financial aspects of failure. Emotion- 
focused coping encompasses activities that help regulate emotional reactions. Singh et al.'s (2007) entrepreneurs use this second type of coping to tackle the psychological and social issues stemming from failure. They report that more coping and learning occur in the economic aspect of the lives of failed entrepreneurs as compared to the social, psychological and physiological aspects. The implication is that the emotional side of venture failure is more challenging to deal with than the practical side of failure. Regarding resilience, Hayward et al., (2010) propose that an entrepreneur’s confidence and even overconfidence can trigger positive emotions that build resilience and increases the likelihood of the failed entrepreneurs starting up another venture.

Altogether, these studies provide valuable insight into entrepreneurs 'recovery from the potentially damaging consequences of failure. To date, the focus in this recovery research has been predominantly on practical issues such as overcoming financial loss (Ucbasaran et al., 2013; Shepherd, Wiklund \& Haynie, 2009), the avoidance of the negative emotions generated by venture loss (Shepherd, 2003, Cope, 2011), or the important economic issue of whether the entrepreneur founds another venture (Hayward et al., 2010; Shepherd, Wiklund \& Haynie, 2009). We contend that this view of recovery is a limited. This is a limitation because entrepreneurial failure has far-reaching implications for founders’ lives, implications well beyond the practical issues focused on to date in research on recovery from failure (Singh et al., 2007; Cope, 2011). Moreover, this view of recovery seems more functional and clinical with predominant emphasis on reduction of symptoms (Lloyd, Waghorn \& Williams, 2008) such as using grief measures to check the extent of negative emotions that entrepreneurs have towards failure. Ucbasaran, Shepherd, Lockett \& Lyon (2013:188) go so far as to say that this recovery perspective is limited in that it normally suggests "simply overcoming" the financial cost of failure. An alternative view of recovery is one that includes a personal process of establishing a meaningful life, in which a person as is having a renewed sense of 
hope, being responsible, feeling a sense of purpose and personally empowered and having the willingness to change life for the better (Lloyd et al., 2008). We propose entrepreneurs’ spirituality as a lens through which failure could be studied in an effort to better understand recovery from the sweeping implications of failure for the entrepreneur. We thus examine the effect of spirituality in the domain of entrepreneurial failure. We believe examining the role of spirituality in the context of entrepreneurial failure is a novel and an alternative approach that can build on this current overarching notion of recovery from failure. Examining failure from a spiritual perspective may reveal fresh insights into not only how entrepreneurs overcome the practical aspects of failure such as bankruptcy but may also enhance our understanding of how they find new meanings and regain hope in what they do next despite having to face the pain and practical challenges of failure.

\section{RESEARCH METHODOLOGY}

\section{Research Design and Context}

We used a narrative approach within an overarching qualitative research design for this study. Qualitative research is recommended when a complex phenomenon such as venture failure needs to be explored in detail and the focus is on understanding the meaning that the participants assign to it (Creswell, 2013). Narrative inquiry has been suggested for entrepreneurship research specifically because it captures a sequence of events like venture founding from the point of view of a participant in that sequence (Endres \& Woods, 2007; Warren, 2004). Narratives produce "rich, thick data” (Willis, 2006: 272) because they are devices of interpretation (Lawler, 2002) through which people make sense of their experiences and use them to elaborate their opinions and give reasons for their actions and intentions (Shkedi, 2005, Richardson, 1990). The uniqueness of narrative is its ability to capture how a sequence of events unfolded over time and affected the people involved (Polkinghorne, 2003). In this study, narratives could reveal how entrepreneurs’ spirituality 
shaped their meaning of venture failure, influenced their responses to the challenges brought about by it, and affected their subsequent career intentions such as the motivation to found another venture. We thus collected and analyzed entrepreneur's narratives of venture failure to examine the research question, “How does spirituality affect entrepreneurs' experience of venture failure?”

The research context was New Zealand, a country ranked third in terms of total entrepreneurial activity of $17.6 \%$ as reported in the Global Entrepreneurial Monitor Report of 2005. This is higher than the global average of $9.1 \%$ and that of USA in sixth position at 12.4\% (Fredrick \& Chittook, 2006: 22). However, higher rates of entrepreneurial activity do not necessarily suggest greater entrepreneurial expertise. New Zealand is also reported to have higher than average venture failure rates (Lee , Yamakawa, Peng \& Barney, 2011), a regulatory environment that is not supportive of failure (Kuruppu, Laswad \& Oyelere, 2003) and a discouraging culture of "tall poppy syndrome” reflected in strong negative public reaction towards failed entrepreneurs (Kirkwood, 2007).

\section{Sampling and Data Collection}

We implemented the purposive sampling approach (Patton, 1990) that involved identifying those examples that would most likely yield rich information about the phenomenon being examined for the study. Nine entrepreneurs were included in this study as they had experienced failure of their small to medium sized venture and had in-depth information of experiencing spirituality while dealing with failure. Table 1 gives further information about the sample. All participants were given pseudonyms to maintain anonymity. We collected data through interviews to ensure in-depth information about entrepreneurs' lived experience of venture failure. Interviews are the predominant method of data collection in narrative research (Creswell, 2013; Elliott, 2005). Interviews were semi-structured reflecting a number of open ended questions and lasted between 1.5 to 2 hours. We also 
collected some data from media articles, websites, email communication and notes from phone conversations with the participants but this served as background data to help verify and flesh out events revealed through interviews (Creswell, 2013).

Insert Table 1 about Here

\section{Data Analysis}

We began by developing a chronology of events for each entrepreneur because individuals do not always tell their stories in a coherent manner that clearly delineates the sequence of events (Creswell, 2013). Next, we coded entrepreneur's individual interviews with a small, initial set of open codes that emerged from our initial reading of interview transcripts and from our knowledge of existing research on entrepreneurial failure (Creswell, 2013). These initial codes were expanded into more detailed codes that became increasingly abstracted from the data (Richards, 2009; Lieblich, Tuval-Mashiach \& Zilber, 1998). We then analyzed across participant's stories in order to identify common patterns regarding the influence of spirituality on entrepreneurs' experience of venture failure. We were looking for patterns in the temporal ordering of events for entrepreneurs as well as for themes within particular time periods (Elliot, 2005). In the end, our evidence revealed a collective narrative (Richardson, 1990) that was illustrative of how spirituality interacted with venture failure, despite the participants coming from different spiritual traditions. 


\section{FINDINGS}

How does spirituality affect entrepreneurs’ experience of venture failure? We present a collective narrative of entrepreneurs' venture failure with a focus on their spirituality and its role in what research shows to be a very difficult journey (Cope, 2011; Shepherd, 2003). As expected, venture failure was a turbulent event that ripped through the very fabric of the entrepreneurs' lives. Participants described having to face the challenges of venture failure as a “bitter” (Garth), “frustrating” (Quinn), “disappointing” (Udela), and a “devastating” time of their life (Andy). They described feeling “on the edge of emotional breakdown” (Andy), “shell shocked” (Dan), being “trapped” and feeling "pressured” (Garth) as they tried to grapple with the consequences of venture failure. Failure affected almost every sphere of the entrepreneurs' lives as they suffered a heavy financial setback for months, consistent with past empirical findings (Singh et al., 2007; Ucbasaran et al., 2013) Harry had to "live in a hand to mouth situation” and "carried on for years with no support to keep the "house fires burning”. Janice had "no house and no job” and described herself as a “displaced person” as a result of the financial setback she experienced. Similarly, Andy described how his life had changed "from being a big time clothing manufacturer to being unemployed and living on the government benefit for 5 years” and that this “was not an easy transition”. Finding employment, fulfilling legal obligations, downsizing or selling personal properties to settle debts and carrying out family responsibilities were ongoing simultaneous battles that seemed never-ending. For several entrepreneurs, the stress in dealing with the sheer scale of changes after venture failure also affected their health and personal relationships. Life overall seemed harsh and unforgiving because of the shattering impact of venture failure.

We were surprised to find, in the collective narrative that surfaced, a positive outcome emanating from venture failure. Despite the clear suffering wrought by failure, it also opened a doorway to deep spiritual transformation. The collective narrative unfolds across two 
temporal periods called 'chapters' as is elaborated in the following two sections. Temporality is a key feature of narrative research and is fundamental to establishing the meaning of events from the point of view of the participants (Elliot, 2005). We label the first chapter as “engaging deeply with venture failure” because it shows how entrepreneurs delved deeply into their venture failure; looking beneath the layers of material losses and personal distress. We label the second chapter as "Evolving spiritually through venture failure" because it illustrates how entrepreneurs gained a better understanding of their inner nature and spiritual insight through venture failure. We present these two sections and describe themes that manifested within each below.

\section{Chapter 1: Engaging Deeply With Failure}

Engaging deeply with failure illustrates how despite feeling overwhelmed with the setback of venture failure; the entrepreneurs delved deeply into this experience to uncover its meaning and to figure out how they could pull through the suffering that was brought about as a result of it. We were somewhat surprised to find entrepreneurs engaged so thoroughly with failure in this initial period given that previous research shows that entrepreneurs can engage in patterns such as denial or distraction/ avoidance behaviour to distance themselves from the painful reality of venture failure (Singh et al., 2007; Ucbasaran et al., 2013). Shepherd (2003) also describes this phenomenon of suppressing feelings of loss and the negativity associated with failure to get on with life.

Within this initial chapter, we abstracted three themes that further show how entrepreneurs engaged deeply with failure. These three themes are presented here along with quotes from the participants to provide a rich description of what was happening for entrepreneurs during this initial period. The first theme was "perceiving failure as part of a greater plan”. Entrepreneurs came to understand venture failure as a milestone in their personal life journey. For example, several participants shared their belief in the presence of a 
higher power or supreme creator and explained that they perceived failure as part of a life blueprint designed by the higher power. This can be seen in Andy’s comment, “God wants to see what you are made of. I was in a really bad spot but in all those difficulties there was this underlying faith that God is good and the long term thing is actually in His hands.” Udela made a similar comment, "We have strong faith and Christian beliefs. We knew God had a plan. At the end of the day, He was preparing us for something and that's why He gave us the business to manage and to lose. We always believe that there is a purpose for what happens to us.” Quinn shared that when failure seemed almost inevitable, he decided to close down the business because he thought that “it must be God's will to get out of it”. He further expressed his belief that, as part of the greater plan, things would improve after closing the business saying that he "always” got "a positive response from God”.

The second theme was "seeing beyond self" and it shows how entrepreneurs began to find inner strength to pull through the suffering of failure. One way in which participants saw beyond themselves was through others and trying to make a difference in others' lives. For instance, Andy described how he and his wife were "involved in volunteering for the community in several countries” and this helped him get through what he described as an “emotionally shattering” phase of his life. He claims he may have "come apart totally” if not for the volunteering as his good friend did. Andy revealed how his friend, an entrepreneur who was in a same industry and was "facing a similar crisis” had "committed suicide”. Andy reported that even though his failure was "stressful", he "never got to the stage of contemplating suicide" because his "strength came from being an active Christian and being committed to a meaningful purpose in life”. Harry alluded to this theme when he talked about seeing his “children and mother as gifts from God". When he was dealing with his entrepreneurial failure, he “connected closer to God not through any statues” but through doing things for the family. Although he had lost nearly everything after venture failure, he 
“focused on relationships and networks" because of his "spiritual belief that one never walks alone and there is always someone there with you”.

Another way in which participants saw beyond themselves was through sensing a higher power. Several entrepreneurs described feeling calmer and stronger when they focused on their “relationship” (Quinn, Harry) with the higher power. For example, Udela "prayed a lot”. Garth “confided in Khudah [God] during this experience”. Similarly, Quinn "shared even the smallest things with God" and Dan felt that his conversations with God helped him during the hardest moments. He "would go to a room and totally lose it [pour out his feelings in front of God]. In doing this he would feel the presence of higher power being there for him and "listening” to him. Kay shared an incident that occurred soon after the venture failed that made him realise the presence of a higher power in his life, “One day I remember walking through the door and wondering that I have never seen a praying mantis catch and eat something. It is strange because two days later when I was working on the computer, a praying mantis landed on the curtain in front of me. A few seconds, later a beetle flew and landed almost straight in its arm. The praying mantis caught and ate it. I was just sitting there overwhelmed because this was happening inside my house in front of my eyes. So I like to believe that there is some higher power out there which does look after you and you will find the answers you are looking for.”

This particular theme echoes common elements present in existing workplace or management spirituality research. In particular, feeling a connectedness with others and a belief in a higher power are common element across definitions of workplace spirituality (Asher \& Lane-Maher, 2004; Corner, 2009; Liu \& Robertson, 2011; Mitroff \& Denton, 1999). However, it is novel to see this element of spirituality surface in the realm of entrepreneurship. The third theme that surfaced was “engaging with failure with spiritual purpose”. It reveals how venture failure became an opportunity for and medium through which entrepreneurs 
could practice spirituality and explore their spiritual beliefs. For example, Garth donated money to the poor after his business failed. He believed that “a poor person's 'dua' [prayer] is answered by Khudah [God] and so a dua would change [his] circumstances”. He described that his father had always helped the poor and he had seen how Khudah took care of his father's family because he helped the poor. Therefore, he believed that if he followed his father's footsteps then Khudah would take care of him and his family too. He preferred doing charity for the poor rather than making contributions towards renovation and redecoration projects for mosques. Similarly, Udela also thought of charity and creating something positive out of the failure of her egg business. She thus donated the remaining eggs to the local church. The church sold the eggs; using the proceeds to buy and distribute Bibles. Janice found venture failure to be “a very hard transition period” but saw a spiritual purpose in the failure. In particular, she believed she and her business partner had previous reincarnations together and Janice was prepared to "lose everything” in order to enable her business partner to learn her life lessons. Janice saw the loss of the business as part of a “contract” for her present life and again, something she could sacrifice if it meant saving helping her partner. She believed even though she lost the business, it would ultimately come back to her, perhaps in a different form, because she had selfless intentions when she let it go. She spoke of business founding as meeting spiritual and emotional needs, not just consumer needs”.

Failure also prompted entrepreneurs to re-examine and even modify their spiritual beliefs. For example, Andy read a few lines in scripture one day while going through his failure experience that "changed [his] whole attitude” and steered [his] life in a "positive direction”. He recalled the words being something like: 'He who lights the fires says the Lord; you should get nothing from me but ashes'. The words resonated for him to the point that he thought God was speaking to him. He decided that he had perhaps been lighting the 
fires by pushing and stressing too much to get on with the next chapter of his life. Moreover, he felt he was only getting ashes in that he was "shattered", and "not sleeping through the night”. Andy ultimately took these words as God speaking to him and realised that he was not allowing God to help him. He "backed off and became relaxed about the whole situation" from that day onwards to allow God to open new doors for him. Kay also engaged with failure for spiritual purposes. He shared his failure story with a spiritual counsellor when he reached a point where he could see nothing but negativity in everything after his venture failed. The counsellor's advice opened his mind to a whole new way of dealing with his ongoing hardships. He elaborated, “You need to wake up every morning and say, 'Today I expect a miracle' and you will get it. That does not mean you will win the Lotto. It means if you expect a miracle each day, you will notice something good will happen. On the contrary, if you expect things to go wrong, then they do go wrong as you will attract negative things”. Overall, this chapter suggests how spiritual beliefs and practices enabled the entrepreneurs to make sense of venture failure.

\section{Chapter 2: Evolving Spiritually Through Failure}

Having engaged deeply with failure, entrepreneurs felt as though they then moved into a period of evolving personally and spiritually. Overall, they found new, predominantly positive meanings from the venture failure and transformed their personalities in a way that reflected increased self -awareness and strength in dealing with hardships. Such a transformation is consistent with evolving spiritually (Corner, 2009; Vivekananda, 2005). To provide a thick description of this period, we discuss four themes that surfaced in our qualitative evidence. The first was "taking positive action”. Specifically, entrepreneurs took actions that that enabled them to feel less like victims and create positivity in their lives. For example, Andy was engulfed with grief and anxiety for months after his venture failed but his life started to improve when he enrolled in a painting course suggested by a friend. He later 
founded a "successful” art gallery based on his new found "passion” and what he had learnt in the painting course. Given this experience, he now believes that "faith" in higher power "needs to be active". His life got better when "on one hand [he] was getting on and doing stuff that helped" and on the other hand he "allowed God to close some doors and open new ones". He shared with us his new spiritual belief that "if one is stationery then it is very hard to go through a door that God might open as the motivation still needs to be there”. Harry also took action to create positivity in his life during this time period. He "totally stopped drinking” alcohol once he realised that he was "lashing out at his children” after consuming alcohol because he “wasn’t handling the reality” of his changed circumstances very well.

The second theme was "becoming more self-aware" theme and involved entrepreneurs coming to a better understanding of their strengths and weaknesses through engaging deeply with failure and its consequences. The entrepreneurs described having greater confidence in their ability to tackle life’s challenges. For example, Garth said that he had "learnt a lot” from failure and had "strengthened his personality”. He also talked about having less fear and insecurity as a result of having to handle the stress that accompanied venture failure. He said, “My other friends are afraid of so many things but I am not afraid and I can deal with any situation. I am not afraid of anything. You can give me the worst of news. Bad news does not shake me. I had so much bad news and stress that now I look at a stressful situation as a list of bullet points. I can go and tackle each bullet point on my own and emerge out of the crisis. This experience of failure has given me the confidence that I will survive through any problem. I know that to accomplish anything you have to give your $110 \%$ and that is why I am doing well today”. Harry also made a similar comment about "not feeling scared anymore of any stressful or challenging situations”. He went on to say that he had become "more mature” as "everyday was a new experience to learn from” and "did not think anything that [he] learnt in the business school taught him or gave him an ability to deal 
with things that he went through”. Udela also mentioned that she learnt many things about herself such as her "ability to cope and how to cope”. She "learnt many interpersonal skills, how to creatively solve problems and how to build professional relationships and how to negotiate with clients". Fiona decided that she "did not want to be involved in a commercial venture again" because her "belief and values were not compatible” with being involved in a commercial venture. She realised that she "hate[s] competition and much prefer[s] collaboration, cooperation and mutual offering”.

The third theme was “affirming a new meaning of venture failure”. It conveys how entrepreneurs began to separate the suffering and negative consequences of venture failure from the valuable lessons and personal growth opportunities that emerged as a result of dealing with it. For example, Udela said, “It is not failure. It is a learning experience and one of the seasons in your life. If you don’t fail, you don’t grow”. She went on to say that “we live in a world where failure is seen as something wrong and bad. The label is attached too early. It may not be the same outcome you anticipated but that doesn't make it a failure. Failure should be quite simply not achieving what you set you to achieve but it doesn't have to be negative”. Similarly, Garth commented, 'What I am today is because of this experience. I know that failure was a bitter experience but it has taught me how to work towards something I want to achieve.” Harry made an analogous comment, “I never imagined going to courts. Venture failure teaches you about life. As an entrepreneur, expect that your business is going to go through tough times. One needs to spend more time on contingency planning beforehand to determine what can happen when things go wrong and how one can deal with it."

The "taking responsibility for mistakes” theme is about the entrepreneurs moving from a position of blaming and being defensive about failure to acknowledging the mistakes they made in their venture that contributed to its failure. For example, Quinn admitted that he 
and his partners “didn’t prepare well before starting the business” and he has now learnt that “without proper thinking, one shouldn’t start any project in life”. Andy described how he could have minimised the financial damage if he had discontinued the venture earlier than he did, “I’ll give you three people as an example. We all owned businesses of the same size. One guy sold out. I was about to sell the business 18 months later but got caught in the financial crisis. The third guy continued the business and later committed suicide. You have got to be able to make fast decisions; you have got to be able to do it because you just can't sit there. I moved too late”. Harry said that although his business was hit by an unexpected disease and regulatory changes, what also contributed to the failure of the business was the fact that that he had not given much thought "on setting up objectives and deciding the structure of the business”. He “just set up the company and got running”. Fiona took “partial responsibility” about what had happened with the venture. She realised that she didn’t have any “interest or skills in finance”. By only staying focused on the innovation part of the business she "allowed [her] preferences to escape” from learning and taking on financial responsibility. Overall, chapter 2 reveals ways in which failure was transformed into a positive experience shaped by the spiritual experiences and ideologies of the entrepreneurs. Figure 1 provides a graphic representation of the chapters in entrepreneurs' collective narrative and a summary of the themes discussed above.

Insert Figure 1 About here

\section{DISCUSSION AND CONCLUSION}

The purpose of this paper was to empirically investigate entrepreneurs' spiritual experience as they dealt with venture failure. According to existing literature, venture failure engenders deep grief (Shepherd, 2003) and has substantial psychological, emotional, and social consequences for entrepreneurs (Singh et al., 2007; Ucbasaran et al., 2013). Failure 
thus offered a unique context whereby we could study how spirituality interacts with this important component of the entrepreneurial process. We thus addressed the specific research question, “How does spirituality affect entrepreneurs’ experience of venture failure?” Our intent was to explore how spirituality could function as a mechanism for coping with and minimizing the effects of venture failure. The collective narrative reported in the findings revealed the phenomenon of venture failure and spiritual experience to be deeply intertwined for entrepreneurs. The two chapters in the narrative showed entrepreneurs actively engaging with failure and the psychological and emotional effects it engendered so that they ultimately transformed the failure into positive life outcomes. In particular, chapter 1 showed entrepreneurs engaging deeply with failure but engaging from a spiritual perspective. This finding was somewhat surprising given what existing literature says about entrepreneurs’ psychological and emotional reactions to failure. Specifically, entrepreneurs can supress these reactions in an effort to quickly move on with their lives (Shepherd, 2003) or engage in reality distortion or self-deception in order to cope particularly with emotional reactions (Singh et al., 2007). We conjecture that it was the spiritual orientation of the present participants that likely explains why they engaged deeply with the failure experience in contrast to entrepreneurs in other studies who were distorting reality. Future research could explicitly compare spiritual and non-spiritual entrepreneurs who experienced failure to test our conjecture.

However, the second chapter in the narrative surfaced an unexpected and rare insight into entrepreneurial failure - the idea that positive outcomes can emanate from failure. The positive outcome was that entrepreneurs felt they had evolved spiritually through their failure experience and were grateful for this evolution. Specifically, failure was a medium through which entrepreneurs gained greater self-awareness and strengthened their personalities in ways that would benefit them no matter what they did professionally in the future. This 
positive outcome for entrepreneurs calls into question the view of venture failure as a completely negative experience for entrepreneurs (Shepherd et al., 2009; Smith \& McElwee, 2011). Our evidence indicates that a more nuanced view of failure and its outcomes would be appropriate in future research. In fact, future research could explore what other factors, in addition to spirituality, might produce positive outcomes from entrepreneurial failure.

Overall, the study has two implications for the wider entrepreneurship literature. First, the findings present an alternative to the prevailing view on recovering from failure. Scholars have stressed the financial and emotional costs of venture failure and have drawn on psychological theories to examine how entrepreneurs can reduce these costs for speedy recovery from this experience (Singh et al., 2007; Ucbasaran et al., 2013). Our empirical evidence highlighted the possibility that entrepreneurs can adopt a spiritual approach to recovery from venture failure. While psychological theories focus on regulating the pain emanating from failure (Shepherd, 2003; Singh et al., 2007), the spiritual approach revealed in current findings encourages entrepreneurs to be open to the pain of venture loss. Fortunately, an openness to this pain ultimately enabled entrepreneurs to evolve spiritually and feel positive about the direction their lives took after failure. We conjecture that the positivity and sense of transformation achieved by entrepreneurs despite failure likely accounts for why one (Andy) was able to found a new business and 7 of the 8 remaining entrepreneurs were open to founding new ventures in the future (see Table 1). This willingness to found new ventures represents a substantive recovery from failure which may contribute to founding of second ventures for these entrepreneurs. The founding of second ventures by entrepreneurs is of great interest to scholars and policy makers alike since entrepreneurs appear to incorporate learning from their initial failure into new ventures, thereby increasing the probability of success for a second venture (Cope, 2011). Future research could systematically explore the extent to which spiritually inclined entrepreneurs 
are more likely to found new ventures after failure. Second, findings have implications for the process of learning from entrepreneurial failure. Scholars hypothesize that learning is a result of critical inward self- reflection, a process that involves entrepreneurs challenging personal assumptions and behaviours in their deliberate attempt to make sense of failure (Cope, 2011; Shepherd, 2003). However, it can be quite overwhelming to confront failure and assess one's responsibility in failure due to the negative emotions interfering with the entrepreneur's ability to process information (Shepherd, 2003). So far there is limited understanding about critical reflection (Ucbasaran et al., 2013), however, our evidence suggests that spirituality sparks this important learning mechanism. Specifically, entrepreneurs critically reflected on and acknowledged their personal contribution to the failure of their businesses. This enabled them to change their mental models about venture founding and gain insight into how they would do things differently if starting up another business. A change in mental models is evidence of critical self-reflection for entrepreneurs (Cope, 2011; Shepherd, 2003).

As with all research, our findings must be considered in light of possible limitations to the present research. One limitation is that evidence was collected in one country, New Zealand. Scholars have pointed out that there are national level differences in entrepreneurial attitudes towards venture failure (Begley \& Tan, 2001; Cave, Eccles \& Rundle, 2001; Damaraju, Barney \& Dess, 2010). We therefore recommend that future research on this important topic be done in other countries and that present findings be regarded as exploratory. Overall, the paper extends our understanding of venture failure by highlighting how spirituality affects venture failure. Specifically, entrepreneurs' spirituality transformed failure into an ultimately positive experience that enabled them to strengthen their resistance to stress, appreciate their connection to others, and become more self- aware as they moved on from the failure experience. As such, findings reveal that positivity can result from entrepreneurial 
failure; in this instance due to the spirituality of participating entrepreneurs. There may be factors other than spirituality that also transform the negativity of venture failure into positive, long term outcomes and we hope the research reported here helps to stimulate future research that uncovers such factors. 


\section{REFERENCES}

Ashar, H. \& Lane-Maher. 2004. Success and spirituality in the new business paradigm. Journal of Management Inquiry, 13(3): 249-260.

Begley, T. M., \& Tan, W.-L. 2001. The socio-cultural environment for entrepreneurship: A comparison between East Asian and Anglo-Saxon countries. Journal of International Business Studies, 32(3): 537-553.

Cave, F. D., Eccles, S.A., Rundle, M. 2001. An exploration of attitudes to entrepreneurial failure: a learning experience or an indelible stigma? Proceedings of the 2001 Babson College-Kauffman Foundation Entrepreneurship Research Conference: Jonkoping, Sweden, May.

Cope, J. 2011. Entrepreneurial learning from failure: An interpretative phenomenological analysis. Journal of Business Venturing, 26(6): 604-623.

Corner, P. D. 2009. Workplace spirituality and business ethics: Insights from an Eastern Spiritual Tradition. Journal of Business Ethics, 85(3): 377-389.

Creswell, J. W. 2013. Qualitative inquiry and research design: Choosing among five approaches (3 Ed.). Thousand Oaks, CA: Sage.

Damaraju, N.L., Barney, J., Dess, G. 2010. Stigma and entrepreneurial risk taking, http://www2.druid.dk/conferences/viewpaper.php?id=502023\&cf=43, Accessed15 ${ }^{\text {th }}$ November 2012.

Elliot, J., 2005. Using Narrative in Social Research: Qualitative and Quantitative Approaches. Thousand Oaks, CA: Sage

Endres, A. M., \& Woods, C. R. 2007. The case for more "subjectivist' research on how entrepreneurs create opportunities. International Journal of Entrepreneurial Behaviour \& Research, 13(4): 222-234. 
Frederick, H., Chittock, G. 2006. Global Entrepreneurship Monitor Aotearoa New Zealand. Unitec New Zealand's Centre for Innovation \& Entrepreneurship Research Report Series, 4(1). Unitec, Auckland, New Zealand.

Hayward, M. L. A., Forster, W. R., Sarasvathy, S. D., \& Fredrickson, B. L. 2010. Beyond hubris: How highly confident entrepreneurs rebound to venture again. Journal of Business Venturing, 25(6): 569-578.

Herriott, E. N., Schmidt-Wilk, J., \& Heaton, D. P. 2009. Spiritual dimensions of entrepreneurship in Transcendental Meditation and TM-Sidhi program practitioners. Journal of Management, Spirituality \& Religion, 6(3): 195-208.

Jackson, J. J., \& Konz, G. N. P. 2006. Spirituality and Entrepreneurs. Journal of Management, Spirituality \& Religion, 3(3): 242-257.

Judge, W. Q., \& Douglas, T. J. 2013. Entrepreneurship as a leap of faith. Journal of Management, Spirituality \& Religion, 10(1): 37-65.

Kauanui, S. K., Thomas, K. D., Sherman, C. L., Waters, G. R., \& Gilea, M. 2010. An exploration of entrepreneurship and play. Journal of Organizational change management, 23(1): 51-70.

Karakas, F. 2009. Spirituality and performance in organizations: A literature review. Journal of Business Ethics, 94: 89-106.

Karp, T. 2006. The inner entrepreneur: A constructivistic view of entrepreneurial reality construction. Journal of Change Management, 6(3): 291-304.

Kirkwood, J. 2007. Tall poppy syndrome: Implications for entrepreneurship in New Zealand. Journal of Management \& Organization, 13(4): 366-382.

Kuruppu, N. Laswad, F., Oyelere, P. 2003. The efficacy of liquidation and bankruptcy prediction models for assessing going concern. Managerial Auditing Journal, 18(6/7): 577-590. 
Lawler, S. 2002. Narrative in social research. In T. May (Ed.), Qualitative research in action: 242-259. London: Sage. Accessed from Ebrary Ebooks 16 May 2011.

Lee, S.-H., Yamakawa, Y., Peng, M., Barney, J. 2011. How do bankruptcy laws affect entrepreneurship development around the world? Journal of Business Venturing, 26(5): 505-520.

Lieblich, A., Tuval-Mashiach, R., Zilber, T. 1998. Narrative Research: Reading, Analysis, and Interpretation. Thousand Oaks, CA: Sage.

Liu, C. H., \& Robertson, P. J. 2011. Spirituality in the Workplace: Theory and Measurement. Journal of Management Inquiry, 20(1): 35-50.

Lloyd, C., Waghorn, G., \& Williams, P. L. 2008. Conceptualising recovery in mental health rehabilitation. British Journal of Occupational Therapy, 71(8): 321-328.

Mitroff, I. I. 2003. Do not promote religion under the guide of spirituality. Organization, 10(2): 375-382.

Mitroff, I.I. and Denton, E.A. 1999. A spiritual audit of corporate America, San Francisco, CA: Jossey-Bass.

Nolan, P. 2005. From first-person inquiry to radical social action. Action Research, 3(3): 297312.

Nwankwo, S., Gbadamosi, A., \& Ojo, S. 2012. Religion, spirituality and entrepreneurship. Social and Business Review, 7(2): 149-167.

Patton, M.Q. 1990. Qualitative evaluation and research methods. Sage: London.

Pavlovich, K. \& Corner, P. 2013.Conscious enterprise emergence: Shared value creation through expanded conscious awareness. Journal of Business Ethics.

Pio, E. 2010. Islamic sisters: Spirituality and ethnic entrepreneurship in Sweden. Equality, Diversity and Inclusion: International Journal, 29(1): 113-130. 
Pinfold, J. 2000. Examining venture failure rates: A New Zealand study. Small Enterprise Research, 8: 56-72.

Polkinghorne, D.E. 2003. Narrative configuration in qualitative analysis. In J.A. Hatch, \& R. Wisniewski (Eds.), Life history and narrative: 239:248. Taylor \& Francis e-library, Ebrary eBooks, 5-24, Accessed16 May 2011.

Porter, M., \& Driver, M. 2012. An interview with Michael Porter: Social entrepreneurship and transformation of capitalism. Academy of Management Learning and Education, 11(3): 421-431.

Richards, L. 2009. Handling qualitative data: A practical guide. Thousand Oaks, CA: Sage.

Richardson, L. 1990. Writing strategies: Reaching diverse audiences. Thousand Oaks, CA: Sage

Shepherd, D. A. 2003. Learning from business failure: Propositions of grief recovery for the self-employed. The Academy of Management Review, 28(2): 318-328.

Shepherd, D. A., Covin, J., \& Kuratko, D. 2009. Project failure from corporate entrepreneurship: Managing the grief process. Journal of Business Venturing, 24(6), 588-600.

Shepherd, D. A., Wiklund, J., \& Haynie, J. M. 2009. Moving forward: Balancing the financial and emotional costs of business failure. Journal of Business Venturing 24(2): 134148.

Shkedi, A. 2005. Multiple Case Narrative: A Qualitative Approach to Studying Multiple Populations. Philadelphia: John Benjamins Pub.

Singh, S., Corner, P., \& Pavlovich, K. 2007. Coping with entrepreneurial failure. Journal of Management \& Organization, 13(4): 331-344. 
Smith, R., \& McElwee, G. 2011. After the fall: Developing a conceptual script-based model of shame in narratives of entrepreneurs in crisis! International Journal of Sociology and Social Policy, 31(1/2): 91-109.

Speca, M., Carlson, L., Goodey, E., Angen, M. 2000. A randomized, wait-list controlled clinical trial: The effect of mindfulness meditation-based stress reduction program on mood and symptoms of stress in cancer outpatients. Psychosomatic Medicine, 62: 613-622.

Ucbasaran, D., Shepherd, D. A., Lockett, A., \& Lyon, S. J. 2013. Life after business failure: The process and consequences of business failure for entrepreneurs. Journal of Management, 39(1): 163-202.

Vivekananda, R. 2005. Practical yoga psychology. Bihar, India: Yoga Publications Trust.

Warren, L. 2004. A systemic approach to entrepreneurial learning. Systems, Research and Behavioral Science, 21(1): 3-16.

Willis, K. 2006. Analysing qualitative data. In M. Walter (Ed.), Social Research Methods: An Australian perspective: 257-280. Melbourne: Oxford University Press. 
Table 1

Description of entrepreneurs \& failed ventures

\section{Pseudonym/ experience}

Fiona

Scientist \& tertiary educator

\section{Udela}

Tertiary educator \&

occupational therapist

Quinn

Tertiary student

Andy
Clothing industry

Harry

Engineer

Garth

Tertiary student

Dan
Tertiary student

Tertiary student

\section{Janice}

Spiritual counsellor

Kay
Tertiary student

\section{Venture Description}

To make her innovative pest trap available to the community, Fiona started a venture in partnership with friends. Partnership, financial \& supplier issues led to venture closure.

Wanting life style change through self-employment, Udela began an egg business with her husband \& friends. The business was closed because of cash flow problems. Quinn \& friends started a travel \& tourism venture; seeking self-employment \& wanting to experience city life instead of the family farm. Capital \& partnership issues led to venture closure.

Interest in clothes \& boosting up of personal finances motivated Andy to start a clothing manufacturing venture. Economic recession \& competition from larger firms led to losses \& firm closure. Harry started a prawn business; wanting self-employment. Change of regulations \& spread of disease led to financial losses, debts \& forced him to sell the business

Need to earn a living motivated Garth to start a poultry business. In adequate funds to tackle business crisis led to firm closure.

\section{David started a construction \& property management} business to pay back his debts and earn a living. Expanding the business without adequate resources led to bankruptcy.

Janice started a grief gift retail business with a friend to support people in their grief. Partnership \& funding issues led to business closure.

Kay started mushroom business for a living \& to follow his passion in mushrooms. Crop disease led to losses \& closure.

\section{After venture failure}

Next career move: Returned to academic job

Future venture? Not interested in commercial venture

Next career move: Continues to work as an academic

Future venture? Open to starting another venture

Next career move: "Successful” marketing professional.

Future venture? Open to starting another venture

Next career move: Founded \& runs a successful art gallery

with his wife.

Future venture? No new venture beyond art gallery

Next career move: Studying towards a business degree

Future venture? Wants to start another venture.

Next career move: Working full time as a marketing professional

Future venture? Open to starting another venture

Next career move: Helped establish and grow other businesses

Future venture? Open to starting another venture Next career move: Looking for full time employment

Future venture? Open to restarting the venture Next career move: Seeking full time employment

Future venture? Open to starting another venture 
FIGURE 1.

Graphic Summary of Chapters in the Collective Narrative

1. Engaging Deeply with Failure

Themes

-Perceiving failure as part of a greater plan

-Seeing beyond self

-Engaging with failure for spiritual purposes
2. Evolving Spiritually through Failure

\author{
Themes \\ -Taking positive action \\ -Becoming more self-aware \\ -Affirming a new meaning of \\ failure \\ -Taking responsibility for mistakes
}

